\title{
Autonomous sound recording outperforms human observation for sampling birds: a systematic map and user guide
}

\author{
Kevin Darras (DD, ${ }^{1,5}$ Péter Batáry (D),${ }^{1,2}$ Brett J. Furnas (D) ${ }^{3}$ Ingo Grass, ${ }^{1}$ Yeni A. Mulyani, ${ }^{4}$ and \\ TEJA TSCHARnTKE ${ }^{1}$ \\ ${ }^{1}$ Agroecology, Department of Crop Sciences, University of Goettingen, Grisebachstrasse 6, 37077 Göttingen Germany \\ ${ }^{2}$ Lendület Landscape and Conservation Ecology, Institute of Ecology and Botany, MTA Centre for Ecological Research, Alkotmány u. \\ 2-4, 2163 Vácrátót Hungary \\ ${ }^{3}$ Wildlife Investigations Laboratory, California Department of Fish and Wildlife, 1701 Nimbus Road, Suite D, Sacramento, California \\ 95670 USA \\ ${ }^{4}$ Department of Forest Resources Conservation and Ecotourism, Faculty of Forestry, Bogor Agricultural University, Bogor, Indonesia
}

Citation: Darras, K., P. Batáry, B. J. Furnas, I. Grass, Y. A. Mulyani, and T. Tscharntke. 2019. Autonomous sound recording outperforms human observation for sampling birds: a systematic map and user guide. Ecological Applications 29(6):e01954. 10.1002/eap.1954

\begin{abstract}
Autonomous sound recording techniques have gained considerable traction in the last decade, but the question remains whether they can replace human observation surveys to sample sonant animals. For birds in particular, survey methods have been tested extensively using point counts and sound recording surveys. Here, we review the latest evidence for this taxon within the frame of a systematic map. We compare sampling effectiveness of these two survey methods, the output variables they produce, and their practicality. When assessed against the standard of point counts, autonomous sound recording proves to be a powerful tool that samples at least as many species. This technology can monitor birds in an exhaustive, standardized, and verifiable way. Moreover, sound recorders give access to entire soundscapes from which new data types can be derived (vocal activity, acoustic indices). Variables such as abundance, density, occupancy, or species richness can be obtained to yield data sets that are comparable to and compatible with point counts. Finally, autonomous sound recorders allow investigations at high temporal and spatial resolution and coverage, which are more cost effective and cannot be achieved by human observations alone, even though small-scale studies might be more cost effective when carried out with point counts. Sound recorders can be deployed in many places, they are more scalable and reliable, making them the better choice for bird surveys in an increasingly data-driven time. We provide an overview of currently available recorders and discuss their specifications to guide future study designs.
\end{abstract}

Key words: acoustic recording; autonomous recording units; bioacoustics; passive acoustic monitoring; point count; sound recorders.

\section{INTRODUCTION}

In the face of the current threats to global biodiversity, ecologists strive to devise efficient survey methods to measure our vanishing, under-sampled biodiversity. We need more extensive sampling coverage on temporal and spatial scales to detect trends across regions and with time (Magurran et al. 2010, Ahumada et al. 2011). We need to sample animals thoroughly to detect species at risk, implement conservation strategies, and monitor their results. Material and personal resources must be deployed with greater efficiency. To enable international cooperation and re-use of data (Wilkinson et al. 2016), a minimal bias should be attained with standardized, comparable, and repeatable sampling methods.

Manuscript received 2 November 2018; revised 17 April 2019; accepted 23 April 2019. Corresponding Editor: Dianne Brunton.

${ }^{5}$ E-mail: kdarras@gwdg.de
Vertebrates pose a particular challenge for sampling because they are mobile, often evading detection (Thompson et al. 1998). Many vertebrates are usually surveyed by direct human observation methods (e.g., point counts, transect surveys) because capture methods are inherently more intrusive and effort-demanding. Human observers rely on aural and visual detection to count animals and identify species, but given that some insects (e.g., cicadas and orthopterans) and most terrestrial vertebrates (birds, amphibians, mammals, some reptiles) commonly use sound, passive acoustic monitoring methods have recently gained more users (Shonfield and Bayne 2017).

For birds in particular, passive acoustic sampling methods have been used extensively and increasingly (Fig. 1). Many different autonomous sound recorders (Merchant et al. 2015, Whytock and Christie 2016) and software solutions for automatic species classification have been developed (Priyadarshani et al. 2018). However, human observation survey methods are still the 
standard, most widely used method (Bibby et al. 2000). Although some research has compared acoustic methods with these traditional survey methods, results were controversial as some studies showed that acoustic surveys detect more bird species than point counts (Haselmayer and Quinn 2000), whereas other studies concluded the opposite (Hutto and Stutzman 2009). A recent metaanalysis found no detectable difference between both methods in terms of species richness (Darras et al. 2018a).

Still, many other points are yet to be discussed to determine how autonomous sound recorders match up against traditional human observation. Bird studies provide ample material for an interesting methodological comparison using a systematic map, which is an overview of the available evidence in relation to a topic of interest (James et al. 2016). Indeed, a qualitative review (Shonfield and Bayne 2017) and a commentary discussing applications and challenges of acoustic data collection in the tropics (Deichmann et al. 2018) have been published recently. An appraisal of passive acoustic monitoring has exposed the opportunities and challenges that the technology presents (Gibb et al. 2018), and a recent systematic review shows that most research using passive acoustic monitoring is focused on bats and northern temperate regions (Sugai et al. 2019).

In the present study, we provide a more comprehensive evaluation of autonomous sound recorders, starting with the comparison with point counts in avian diversity research. We use a systematic map of studies that surveyed birds with both survey methods paired, and discuss the inherent advantages of either method using additional references. We focus on their sampling effectiveness, their output variables, and practicality aspects.

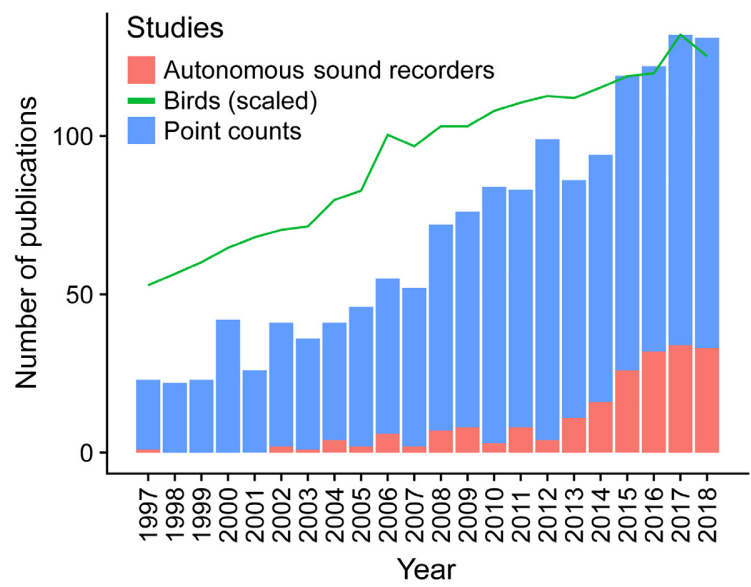

FIG. 1. The number of publications per year mentioning autonomous sound recorders or point counts (excluding recorders) from ISI Web of Knowledge. Records start with the first occurrence of recorders in 1997. The green line shows the trend in the number of publications in ornithology, scaled by the maximum number of publications shown in the bars.
We provide a table summarizing pros and cons succinctly to help design future studies, and we present different cost scenarios. We also show the latest results of our previously published meta-analysis, including four more studies, linking to a figure that will be updated as the literature body grows. Additionally, we present a guide of currently available autonomous sound recorders for prospective users, also linking to a comparison table that will be updated as new autonomous sound recorders are launched. We finally give perspectives and identify challenges and remaining knowledge gaps for realizing the potential of autonomous sound recorders.

\section{Materials And Methods}

\section{Systematic map}

We conducted a systematic map, which is an overview of the available evidence in relation to a topic of interest (James et al. 2016). We aimed for an unbiased comparison of bird sampling methods based on autonomous sound recordings vs. those based on direct human observation. However, publications about bird surveys are too numerous to review, and most survey methods based on autonomous sound recorders and human observers are not equivalent, so that separate literature searches on both topics would not be effective for our systematic map. Thus, we decided to search only for publications where comparable sampling methods were used (both humans and sound recorders) for our quantitative analyses. We complemented this comparison with additional relevant articles to discuss more broadly how human observers perform against autonomous sound recording.

Mobile autonomous sound recording devices have not yet been developed for terrestrial habitats, consequently, the majority of studies comparing human to recorder-based surveys directly did point counts (Wimmer et al. 2013), where observers stay in one place, rather than transects, where human samplers are moving. Point counts are written records of the birds detected aurally and visually by a human observer from a fixed position during a specified duration. Similarly, sound recorders generate audio records of birds recorded from a fixed position during a specified time, which are then processed to obtain records of the bird detections. Both of these bird sampling methods yield bird detections data, which are a record of the number and species of birds detected in a particular site and time (Fig. 2). These data can be used to derive occupancy, density and abundance, species richness, and vocal activity of birds.

We searched for studies comparing point counts to sound recorders and reviewed them. Scientific publications were retrieved on 17 April 2019, using the following search string combination in ISI Web of Science Core Collection (Citation Indexes) covering all years: TS $=(($ bird* OR avian OR avifaun*) AND ("sound 


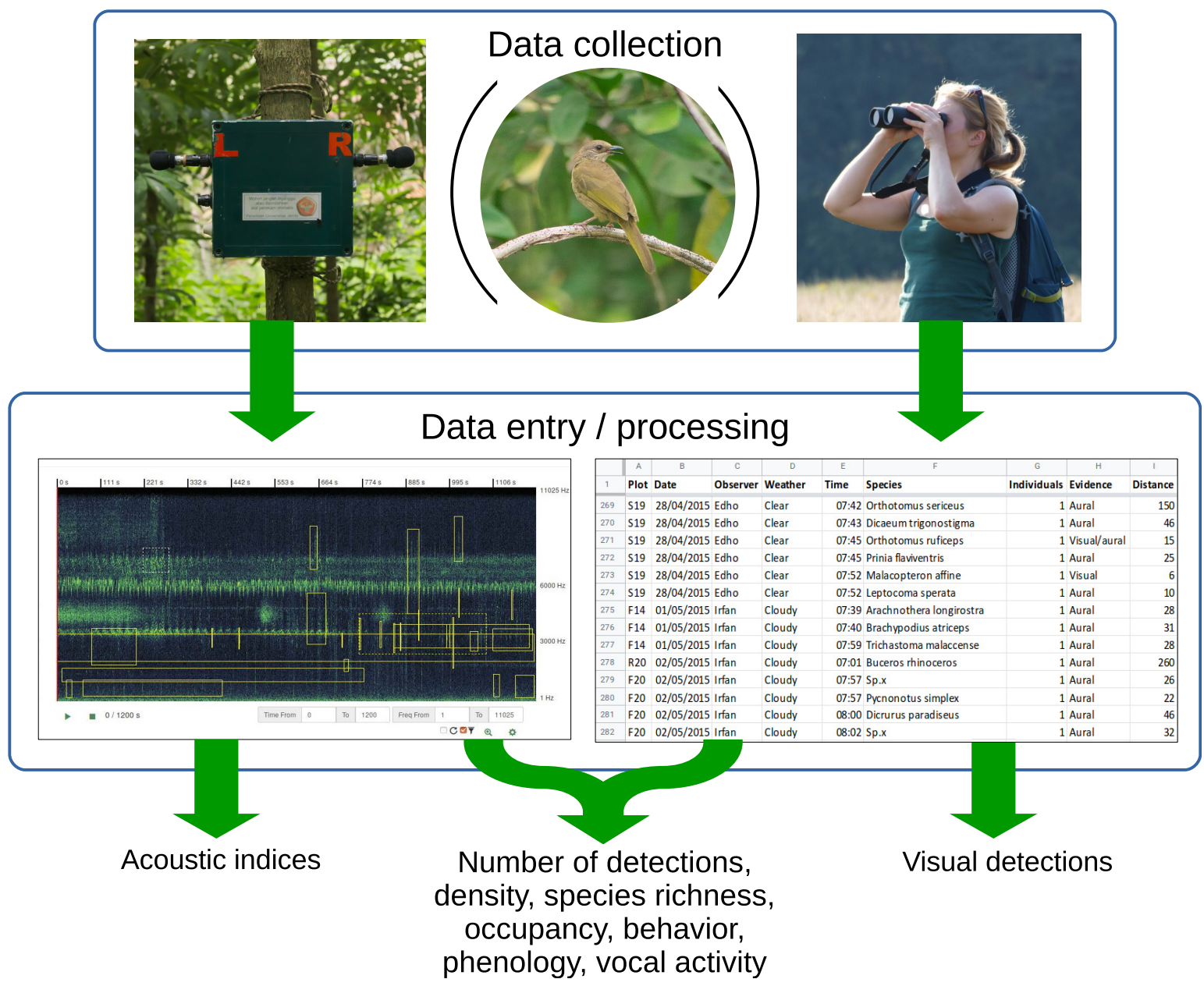

FIg. 2. Overview of the data collection and processing workflow for point counts and autonomous sound recorders. Recorder photo: Patrick Diaz. Point counts photo: Summer 2017 by Joachim Rutschke, calcareous grassland in Ehra-Lessin, Landkreis Gifhorn, Germany. Screenshot of spectrogram from Biosounds (http://soundefforts.uni-goettingen.de/).

record*" OR "acoustic record*" OR "automated record*" OR "acoustic monitor*" OR "recording system*") AND ("point count*" OR "bird count*" OR "point survey*" OR "point-count*" OR "point transect*")). We used the following search string for Google Scholar: "point count" AND "sound recording", sorted by relevance, checking all search results.

We screened all articles to determine the relevance of each study for the systematic map. Only peer-reviewed references in English were considered. Studies that discussed and compared both acoustic and observational bird survey methods were included in our systematic map. Relevant full text publications were retrieved and read entirely. We found 49 studies with our Web of Science search string and 222 studies through Google scholar. We used these studies to structure our methodological comparison and complemented the discussion using references cited in these studies and with additional external, relevant articles.

\section{Overview of recorders}

For the overview of currently available autonomous recorders, we included all recorders that can currently be purchased as of 17 April 2019, and also those that are open source and can be built with freely available instructions (Turner 2015, Whytock and Christie 2016, Sethi et al. 2017, Beason et al. 2018). We compiled and calculated comparable specifications for all recorders by screening technical documentation or asking manufacturers directly. We refrain from recommending any particular model as the best choice will depend on project needs and budgets. However, we explain the relevance of the technical specifications for acoustic studies.

\section{Publication trends}

We generated an overview of the publication trends with time for each sampling method. We queried ISI 
Web of Science on 17 April 2019, covering all years and indices: SCI-EXPANDED, SSCI. We used the search string TS $=(($ bird* OR avifauna* OR avian OR ornitho$\left.\log ^{*}\right)$ AND ((autonom* OR automat* OR unattend*) AND (sound* OR acoustic OR audio) AND (record* OR monitor*)) ) for autonomous sound recorders, and TS $=(($ bird* OR avifauna* OR avian OR ornitholog*) AND ("point count*") NOT ((autonom* OR automat* OR unattend*) AND (sound* OR acoustic OR audio) AND (record* OR monitor*))) for point counts, excluding autonomous sound recorders. We retrieved the number of publications for the field of ornithology over the same time range, queried using TS $=($ bird* OR avifauna* OR avian OR ornitholog*), refined by the Web of Science categories of ecology, zoology, ornithology, biodiversity conservation, environmental sciences, and forestry. The script and data needed to reproduce the graph are in Data S1.

\section{Analysis of survey costs}

To illustrate the costs of different studies based on autonomous sound recorders or human observers, we estimated the total costs in US\$ (material, travel, and labor) required for both survey methods using all possible combinations of the following parameters ( $\mathrm{R}$ script in Data S1): recorder prices and numbers, total sampling time in minutes per site, daily sampling time per site, expert ornithologist daily wages, technician daily wages, site numbers, transport costs, and average site-tosite transport durations. Our calculation considered the number of trips required depending on the type of survey method and the autonomy of the recorder. We used a constant continuous recording autonomy of $200 \mathrm{~min}$, which is representative of most audible sound recorders. The costs of human observers were defined as follows: (total sampling time per site $\times$ number of sites $\times$ expert wage $)+$ (transport cost + transport time $\times$ expert wage) $\times$ (total sampling time per site/daily sampling time per site) $\times$ number of sites. The cost of using recorders was defined as follows: (recorder price $\times$ number of recorders) + (transport cost + transport time $\times$ technician wage $) \times(1+$ ceiling(total sampling time per site/ recorder autonomy)) $\times$ number of sites. We compare costs of both survey methods for four different scenarios representing different study types: conservation studies for rare species (inspired by Holmes et al. 2014), largescale rapid assessments (inspired by Furnas and Callas 2015), and bird community surveys (in tropical vs. temperate zones).

\section{COMPARISON OF SURVEY METHODS}

First, we detail aspects of sampling effectiveness, which we define as the ability of either method to detect birds that are present: visual detections, the avoidance effect, and overlooked birds. We also discuss the sampling of rare species and the feasibility of hybrid approaches combining both methods. Second, we compare the output variables of both survey methods: number of detections, density, species richness, occupancy, behavior, phenology, acoustic indices, and vocal activity. Last, we discuss practicality issues such as standardization, verification and updates, travel time, scaling in space and time, expert labor, automation, material and labor costs, mobility, and sampling after rain. Our results are synthesized in Table 1. Even though some of the studies from our literature search used regular sound recorders, we primarily expose the features of autonomous sound recorders, which have several additional, unique advantages due to their outdoor usability and the possibility of scheduling unattended recordings.

\section{Sampling effectiveness}

Visual detections.-Point count data include visual detections, which is an undeniable advantage. Too few of the studies comparing point counts with sound recordings report the proportion of visual-only detections for carrying out a quantitative analysis. Hutto and Stutzman (2009), who had 7\% visual-only detections overall (Richard Hutto, personal communication), showed that they were the main reason why detections within $100 \mathrm{~m}$ of the recorder were missed in recordings. In open habitats, visual detections can be more common; however, even there, point counts do not have a large advantage. In open woodland savanna, Alquezar and Machado (2015) had only $8 \%$ visual-only detections in point counts; in a mixture of open and wooded sites, CelisMurillo et al. (2012) found 5\% visual-only detections (Antonio Celis-Murillo, personal communication) and they also argue that visual detections do not provide a great advantage, which is echoed by Hingston et al. (2018). Vold et al. (2017) showed that even in tundra bird communities, visual obstruction was not associated with detected bird abundance. In more heterogeneous montane habitats, McGrann and Furnas (2016) detected only $1 \%$ of birds just visually and in forest, Darras et al. $2018 b$ detected only $4 \%$ of birds just visually. Moreover, visual detections mostly concern birds flying over the sampling point, which have large ranges and are relatively unrelated to the sampled location (Kułaga and Budka 2019). In habitats where vegetation obstructs the observers' sight, the low proportion of visual detections is primarily due to visual ranges being much shorter than acoustic ranges. Eventually, most birds vocalize, so that they can be detected in longer duration recordings. Also, a human avoidance effect might exacerbate the problem by keeping birds out of sight of the observers.

Avoidance effect.-Human observers introduce an avoidance effect, especially when there is more than one (Hutto and Mosconi 1981). Disturbance effects from observers on birds are not well documented (but see Fernández-Juricic et al. 2001). Distance-sampling approaches can show that bird detections close to the 
TABLE 1. Comparison of strengths (+) and weaknesses ( - ) of point count and automated sound recording methods for surveying birds. Equal signs (=) denote similar performance.

\begin{tabular}{|c|c|c|c|}
\hline Criteria & $\begin{array}{c}\text { Autonomous } \\
\text { sound recordings }\end{array}$ & Point counts & Main justification \\
\hline Visual detections $\dagger$ & - & + & sound recordings are audio only \\
\hline Avoidance effect & + & - & humans disturb birds \\
\hline Overlooked birds $\dagger$ & + & - & recordings can be played back \\
\hline Rare species & + & - & rare species easily detected with longer recordings \\
\hline Number of detections $\dagger$ & - & + & easier to measure in point counts \\
\hline Density & $=$ & $=$ & densities can be estimated \\
\hline Species richness & + & - & recorders more effective overall \\
\hline Occupancy & + & - & easier to collect replicates with sound recorders \\
\hline Behavior $\dagger$ & - & + & no visual observation data for sound recorders \\
\hline Phenology & + & - & long periods of time easily sampled with recorders \\
\hline Acoustic indices & + & - & measurable only with sound recorders \\
\hline Vocal activity $\dagger$ & + & - & measurable easily with sound recorders \\
\hline Standardization $\dagger$ & + & - & identical sampling possible with multiple recorders \\
\hline Verification and updates $\dagger$ & + & - & audio evidence always available \\
\hline Travel time $\dagger$ & + & - & recorders superior when there are three or more visits per site \\
\hline Scaling & + & - & sound recorders can sample anytime and cover large regions \\
\hline Expert labor $\dagger$ & + & - & sound recorders rely less on human expertise \\
\hline Material and labor costs & $=$ & $=$ & context dependent \\
\hline Mobility & + & - & recorders can be deployed in many places \\
\hline Sampling after rain & - & + & wet microphone windscreens block sound \\
\hline
\end{tabular}

$\dagger$ Denote criteria for which regular sound recorders deliver the same results as autonomous sound recorders.

observer are lower than predicted, especially when excluding data from predominantly close range visualonly detections (Darras et al. 2018b). Even clothing color influences birds' responses to human observers as seen in a reduction in detection probability when observers wear hunter-orange vests (Gutzwiller and Marcum 1993). The calling activity of birds can also be affected by human presence (Bye et al. 2001). On the contrary, it is possible that some curious birds, which are patrolling their territory, are attracted by human presence (like some true babblers in tropical forests or Corvidae in temperate regions). Furthermore, birds can also be unaffected by human observers, as determined by a study locating birds with a microphone array when human observers are present or absent, even though the authors were careful not to generalize their results to other bird communities (Campbell and Francis 2012). The avoidance effect could depend on the bird community and sampling habitat: as Prabowo et al. (2016) illustrated based on detection distances (Fig. S1), birds in disturbed systems tend to be attracted to human presence, while birds in natural systems tend to avoid it. Finally, the avoidance effect can be mitigated by camouflaged bird watching hides. Seeing that the currently available evidence is inconclusive, and the fact that distance sampling is rarely used (Buckland et al. 2008), an overall synthesis or meta-analysis of point count data based on detection distances would be helpful to determine the conditions in which the avoidance effect occurs. Overall though, humans introduce a bias in the bird observation data, and in contrast, there is no reason to believe that the smaller, immobile, odorless, dull-colored, and silent autonomous sound recorders would affect birds.

Assuming that autonomous sound recorders lack an avoidance effect, they should yield more detections close to the survey center. This is useful when bird surveys are carried out on small plots (home gardens, small holdings, etc.) where human presence would affect birds in the entire plot, or even in open habitats, where human observers are too visible. The fact that the sound recordings put more weight on the center is also convenient when environmental covariates are measured close to it, enabling a closer linkage between these and bird community variables.

Overlooked birds. - In point counts of species-rich sites, birds can be overlooked (or rather, not heard) when they occur simultaneously or because of human error, especially during the dawn chorus or the first minutes of the study (Hutto and Stutzman 2009). Abundance can also be underestimated for common birds (Bart and Schoultz 1984). In contrast, sound recordings can be played back repeatedly, often leading to higher detectability for infrequently vocalizing birds (Celis-Murillo et al. 2012). Campbell and Francis (2011) showed that people simulating "blind" point counts (by listening to uninterrupted sound recordings only once) detected consistently fewer species than were present in the recordings. In the previous study, listeners did not visualize spectrograms (i.e., sonograms), which are routinely generated and inspected while listening to audio recordings, so that, in a sense, bird calls can actually be detected both visually 
and aurally. Spectrograms can even be used exclusively to detect single species of interest visually, faster than by listening to the recordings (Swiston and Mennill 2009). This further lowers the chance of missing birds in sound recordings, especially when higher frequency hearing ability declines with age, which affects data from point counts (Emlen and DeJong 1992, Gates and Mills 2005).

Sampling rare species.-Ecologists are debating whether sound recordings are more or less effective than point counts in detecting rare birds. Rare birds, even if they vocalize often when present, would vocalize rarely overall. As Celis-Murillo et al. (2012) pointed out, point counts were more effective in some studies at detecting rare birds (Haselmayer and Quinn 2000, Hutto and Stutzman 2009), possibly because visual cues allow rare birds to be identified with more certainty (Hutto and Stutzman 2009, Leach et al. 2016). However, in the latter studies (which used identical microphone elements), the sound recorders had shorter detection ranges than the unlimited range point counts to which they were compared: Hutto and Stutzman (2009) found that most detections missed by sound recorders were too distant to be recorded (52.7\%). Probably, for vocalizing birds and with identical detection ranges, rare birds are not inherently more detectable with either method. Venier et al. (2012) even argue that detecting rare species is more cost effective with autonomous sound recorders because of easily repeated, unattended sound recordings that can span much longer durations than in-person visits that are inherently more limited in time. Indeed, relatively long recordings have successfully been used for monitoring the rare Western Capercaille (Abrahams 2019). It follows that passive acoustic monitoring systems have a greater potential for detecting rare species or confidently concluding their absence, especially when combined with automated identification algorithms, which can scan long duration recordings (Tegeler et al. 2012).

Combining point counts with sound recorders.-In the light of the specific advantages offered by each survey method, it appears desirable to combine point counts with autonomous sound recorders. When less vocal birds are important, combining both methods can increase the chances of detection of relatively silent birds, even though this can also be achieved by processing longer duration recordings with automated detection methods (see 4.1 in Darras et al. 2018a). Using both methods has been recommended for surveying rare bird species at risk (Holmes et al. 2014) and forest birds (Bombaci and Pejchar 2019). There is usually considerable overlap in the species detected by each method (Darras et al. 2018a) but data from both methods can be combined to detect all unique species (Leach et al. 2016). Also, combining point counts with acoustic recordings can support observers with limited ornithological experience (Wheeldon et al. 2019). Presence/absence data from sound recordings can be merged with point count data, leading to more complete assessments of the bird communities (McGrann and Furnas 2016). Abundance data from either survey method can also be made comparable through modeling that addresses differences in detection probability (Royle and Nichols 2003). Even though skilled personnel is not always available to conduct point counts in these hybrid surveys, occupancy modeling can handle missing data, thus studies can even be designed with point counts conducted at a portion of the sites where sound recorders are deployed. If point counts can be conducted while deploying and retrieving the sound recorders, species richness and occupancy results can be made directly comparable by correcting for heterogeneity in detection probability among survey methods (Furnas and McGrann 2018). However, the added logistical effort (when ornithologists are not available) and statistical complexity (for assessing mixed data sets of different sample numbers and survey method) of such hybrid surveys should be carefully considered.

\section{Output variables}

Number of detections. - Rough abundance estimates are readily obtained from the number of detections in point counts, since it is intuitive to estimate the position of the birds and relate it to previous activity as to guess individuals' numbers. Abundance estimates are generally deemed robust, in spite of high variation at the site level (Toms et al. 2006). However, especially in dense habitats, birds are rarely seen and hard to distinguish anyway, so that we cannot know whether two non-simultaneous sightings of the same species correspond to different individuals. We recommend a more conservative estimate of abundance: the maximum number of simultaneously detected individuals of one species, summed over all species. It has been used in point counts (Teuscher et al. 2015) and is easily applicable to sound recordings. Still, it is also possible to count uniquely identified individuals in stereo recordings in a similar manner as in point counts because the birds' location is audible (Hedley et al. 2017). Individual birds also have unique calls that can be distinguished from another upon close analysis (Beer 1971, Ehnes and Foote 2015), and software solutions tackle this (Ptacek et al. 2016). Four of the publications included in our literature search estimated abundances from sound recordings (Hobson et al. 2002 Sedlacek et al. 2015, Wilgenburg et al. 2017, Bombaci et al. 2019), and they found that abundance estimates correlated strongly with those obtained from point counts, even though species occurring in flocks can be underestimated in sound recordings (Sedláček et al. 2015). Indeed, it can be challenging to measure abundance from sound recordings when large groups of animals are recorded (Denes et al. 2018), but this challenge is also present in bird point counts. More studies should test whether sound recordings can yield accurate abundance estimates. 
Density.-Going further than simple abundance estimates derived from the number of detections, the estimation of bird densities and true abundances requires estimating detectability, which itself relies on bird detection distances (Buckland et al. 2008). The estimation of bird distances in point counts can be inaccurate (Alldredge et al. 2007). Even though the distance is measured, it is also often an estimation based on the presumed bird position, except when it can be seen. Distances to landmarks can be measured before the point count starts to be used as references in estimating distances, and sometimes, when visibility allows, laser rangefinders can also be used to measure distances accurately. When using sound recordings, however, Hobson et al. (2002) previously suggested that spectrograms could be used to estimate bird call distance when the sound source level is known. Indeed, when microphones are calibrated and transmission patterns are known, it is theoretically possible to calculate a detection distance (Darras et al. 2016a), even though there is much variation in acoustic directionality (Patricelli et al. 2007) or loudness of bird calls. Previously, Shonfield and Bayne (2017) also stressed that more work is needed to estimate distances to birds in sound recordings. We showed that listeners that are familiar with the real-world loudness of bird vocalizations can estimate distances to birds reliably by using test sound sequences of known distances as a reference, enabling the use of distance sampling with sound recordings (Darras et al. 2018b). In that context, simultaneous point counts can be useful to gather reference material from aural bird detection at measured distances. Reference recordings of birds at known distances can also be used to fit models of how the vocalization loudness decreases with distance to infer detection distances (Sebastian-Gonzalez et al. 2018, Yip et al. 2019). Taking all the evidence together, bird densities can be obtained both from human observer and sound recording surveys.

Species richness.-Point counts and acoustic recordings can both be used to estimate species richness. There is much debate among traditional and more technologyinclined ornithologists whether sound recorders can detect as many bird species as human observers. A recent meta-analysis measured the performance of sound recorders, measured in terms of species richness, against the performance of human point counts when identical sampling durations are used and detection ranges are considered (Darras et al. 2018a). It showed that the key aspects differentiating sound recorders from human point counts that were mentioned previously, namely visual detections, avoidance effects, and overlooked birds, appear to have no detectable overall negative impact on the performance of recorders vs. humans. Here, we depict updated results of the same meta-analysis, which now includes four new studies and one that was previously not considered (Campbell and Francis 2011, Hingston et al. 2018, Kułaga and Budka 2019,
Wheeldon et al. 2019) in Fig. 3. These new results reveal that recorders record a $11 \%$ significantly $(P<0.05)$ higher species richness per sampling site.

However, for either acoustic recorders or point counts, naive estimates of richness based solely on the number of species detected will be biased low if site-level detection probability is $<1$, which is frequently the case in avian studies (Bibby et al. 2000). Numerous historical and current studies are limited to these measures of apparent species richness, in part because there was only a single survey at each site or repeat surveys did not occur within a short enough period of time to assume population closure. In the next section, we discuss occupancy modeling methods that address this bias.

Occupancy--Occupancy is the proportion of a study area over which a species occurs; it is frequently used as a proxy for abundance (MacKenzie and Nichols 2004) and it can be estimated using occupancy modeling that corrects for bias due to detection probability (MacKenzie 2006). The occurrence probabilities of numerous species and the richness of the entire community can be robustly estimated in a single model by using the standard technique of multispecies occupancy modeling (Iknayan et al. 2014). It requires a series of temporally replicated surveys over a short period of time when populations can be assumed closed and it is well-suited for use with point counts and acoustic recordings that survey multiple species simultaneously (Tingley et al. 2012, McGrann and Furnas 2016). However, it is more practical to use autonomous sound recorders to obtain multiple $(>3)$ survey replicates at comparable times of the day (Brandes 2008). For example, Furnas and McGrann (2018) found that average detection probability of temperate forest passerines per 5-min survey was similar for automated recorders and 50-m point counts, about 0.25 , which suggests that six survey replicates would achieve a site-level detection probability higher than 0.8. False-positive, or misclassification errors, can bias the results but can also be accounted for (Barré et al. 2019) and can also be addressed through more complex hierarchical modeling methods (Royle and Link 2006, Chambert et al. 2018). An important first step that can be used with either standard occupancy or false-positive modeling is to validate the raw survey results by having at least two experts review species detections to identify and resolve discrepancies before occupancy modeling, which is only possible with audio recordings.

Behavior-Visual point count detections can yield data about behavior, food items, occurrence strata, sometimes even the sex and age of the bird. Such data are auxiliary and seldom used in studies designed for measuring avian diversity and community composition, as it can be challenging to get a data set large enough for statistical analysis. However, these data are useful to put results from avian studies into perspective, so we shortly discuss them 


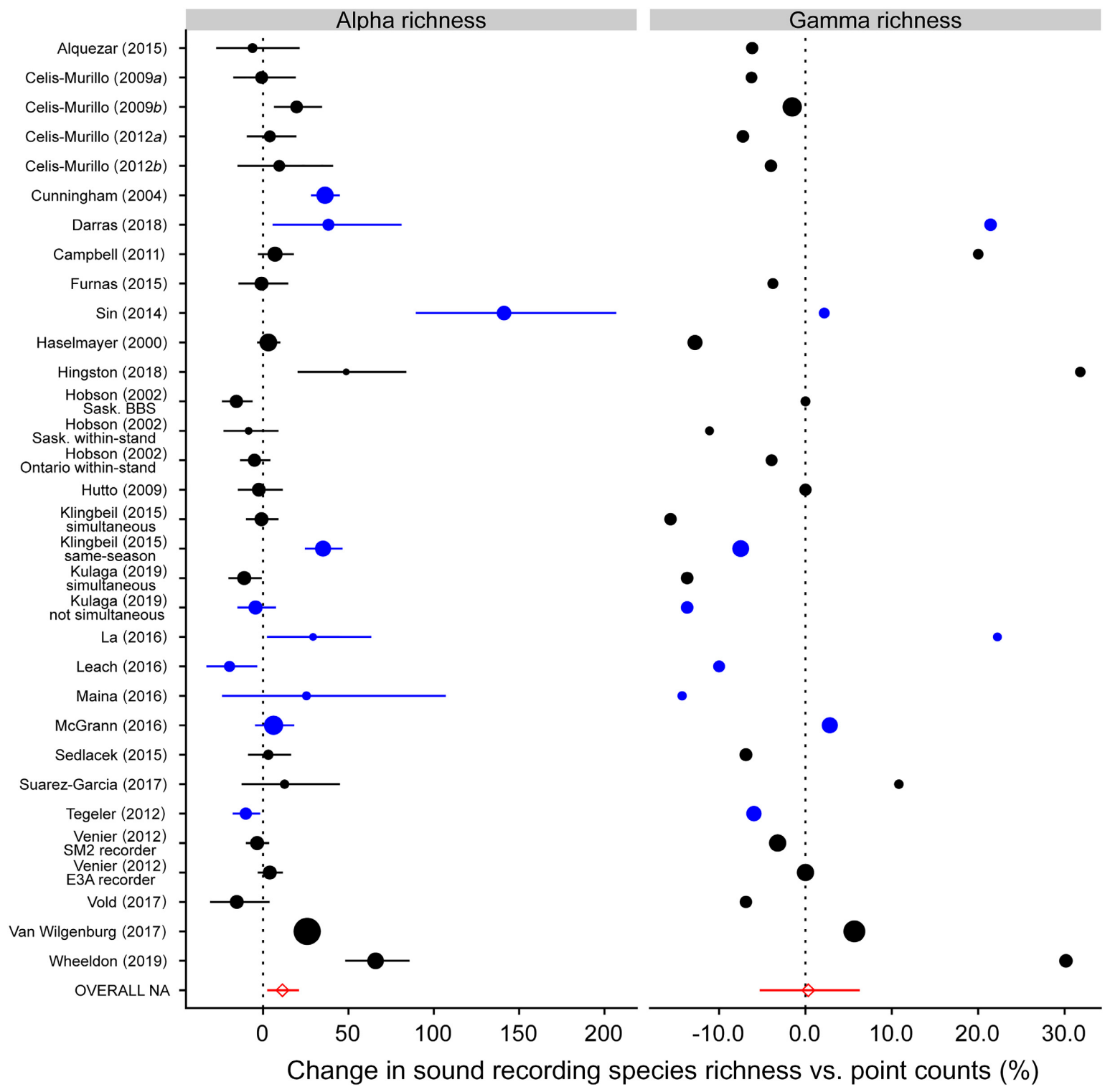

FIG. 3. Response ratios of bird species richness sampled by automated sound recorders compared to point counts with equal sampling durations. Alpha richness is the number of species per site, gamma richness is the number of species overall. The error bars display 95\% confidence intervals and indicate a significant $(P<0.05)$ difference from the control (point counts) when they do not overlap the zero value marked by the dotted line. The dot size and study weight are proportional to the number of sites for alpha richness and total survey time for gamma richness. Blue dots represent studies in which sound recordings were not simultaneous with point counts. Red diamonds represent the overall effect. Reproduced in an updated version with permission from Darras et al. (2018a), updated version available from Darras (2019).

here. To some degree, sound recordings can also convey information through bird vocalisations, since they have different functions: territorial advertisement, mate attraction, and alarm calls all relate to bird behavior. Also, distinguishing between songs, which are typically territorial, and calls can reveal whether the habitat is suitable for breeding or only visited by stray or foraging birds. Bioacoustic monitoring can even support monitoring threatened species for "acoustic conservation behavior" studies (Teixeira et al. 2019). https://onlinelib rary.wiley.com/doi/full/10.1111/csp2.72. It is also possible to infer habitat use by pinpointing the animals' position (Bower and Clark 2005), and by tracking moving birds with microphone arrays (Blumstein et al. 2011). Finally, miniaturized acoustic recording devices could theoretically be installed directly on birds to study physiology and behavior; this is already used for terrestrial mammals (Lynch et al. 2013).

Occupancy modeling also allows drawing inferences about avian behavior based on differences in the frequency 
of vocalizations. In such instances, there is often high statistical power to test behavioral hypotheses because inferences are directly linked to detection probability, which is informed by the full detection history, not just the number of sites where a species was detected. In one recent example, migratory songbirds were shown to sing more than residents on hot days even though this activity is metabolically expensive (McGrann and Furnas 2016).

Phenology. - With sound recordings spanning long time periods, temporal dynamics throughout the day, between days, and between seasons can be analysed, and phenological trends and fine-scale temporal dynamics can be assessed (Blumstein et al. 2011, Lellouch et al. 2014, Thompson et al. 2017). This is especially important for monitoring climate change impacts to birds, which include advancement and mismatch in the phenology of migration and reproduction (Parmesan 2007). The Eurasian Bittern has been monitored over five years using sound recorders, allowing researchers to describe how their spatial distribution, derived from occupancy modeling, responded to habitat structure changes (Frommolt 2017). Acoustic recordings and point counts have been used in occupancy modeling to estimate the date of peak vocal activity of songbirds as an indicator of breeding phenology (Furnas and McGrann 2018); recordings had an advantage over point counts because phenology inferences are based on the detection probability parameters, the precision of which are directly increasing with the number of survey replicates. Open-source automated detection methods also exist to process large phenological data sets spanning thousands of hours (Potamitis et al. 2014). With sound recorders, it is also possible to sample the exact same times of day at multiple sites for unbiased comparisons of phenology.

Acoustic indices.-Sound recordings provide continuous audio records where human observation only provides a filtered interpretation of the original audio-visual events. Using sound recordings, one can generate sound diversity indices (e.g., acoustic richness or dissimilarity; Sueur et al. 2008) for large data sets computationally, which can correlate well with field measures of species richness (Depraetere et al. 2012). However, there are notable differences among the indices, and some authors caution against adopting them too early or widely (Mammides et al. 2017, Jorge et al. 2018). Still, combining the most informative indices in statistical models can accurately predict terrestrial species richness $\left(R^{2}=0.97\right)$ using only recordings (Buxton et al. 2018b), thus bypassing the time-consuming process of identifying species from recordings manually. An added advantage is that all sonant animal taxa are included in audio recordings, allowing a more holistic biodiversity survey that would be difficult to conduct with human observers who are usually specialized on particular taxa. For example, anuran surveys are also often made by human observers, but passive acoustic monitoring is increasingly used
(Koehler et al. 2017). Recording full-spectrum audio gives access to a relatively new field of research called soundscape ecology, which focuses on the entirety of biological, geophysical, or anthropogenic sounds emanating from landscapes (Pijanowski et al. 2011).

Vocal activity. - Vocal activity of birds can be measured in time as an alternative to abundance. Cunningham et al. (2004) showed that vocal activity and abundance are only weakly related, meaning that it represents a different measure. The time that birds spend on calling and singing allows weighing detections more meaningfully: very short detections of birds who are only calling once when they pass by the sampling location should not be considered equivalent to detections of continuous bird songs that span the entire survey duration. Also, detecting bird songs, as opposed to calls, implies that the singing bird is defending a territory or attracting mates (Catchpole and Slater 2008), which is an important distinction that underlines the importance of the habitat in which it is detected. Bird vocal activity should correlate better with bird activity than abundance, which does not consider the duration of the bird's detection. Thus, vocal activity potentially represents a more relevant measure for functional analyses of bird communities. For measuring vocal activity, sound recordings are inherently better suited, as one can take the time to pinpoint the timings when birds are vocal without error. In point counts, the time of the first detection cue is commonly tracked, however, recording the end of the birds' vocalisations is much more challenging, especially when multiple individuals and species are being observed. Thus, sound recordings are better suited for measuring vocal activity than point counts.

\section{PRACTICALITY}

We depict and compare the data collection and entry procedure when doing point counts vs. using autonomous sound recorders in Fig. 2 and detail it here. Standard recommendations have been made for conducting point counts (Bibby et al. 2000), during which an observer stands in the middle of the sampling site and counts birds heard or observed for a specific duration. Field notes serve as a basis for entering data into digital spreadsheets later. Sometimes, audio recordings are made to assist with identification later, and doubtful aural detections can be re-checked. Binoculars routinely support the identification of visual detections and in rare cases, photographic data may complement the survey.

Standard recommendations exist for using autonomous sound recorders (Abrahams 2018, Darras et al. 2018a). Recording schedules are programmed before installing recorders. On-site, recorders should be installed on a support at a constant height. The recorders' function can be shortly checked. Test sound recordings from known distances can be recorded for doing distance sampling (Darras et al. 2018b) or for 
measuring sound detection spaces (Darras et al. 2016). Recorders will start recording at their programmed time, and they are retrieved after the program ends. Typically, batteries are swapped, data are checked and backed up, and after this, recorders can be installed again. Finally, the retrieved data can be processed in different ways: The recordings can either be analysed directly for computing acoustic indices, or they can be processed with automated classification software or manual identification using spectrograms and sound playback.

Standardization.-We discuss standardization by assessing the features of either method that enable unbiased comparisons of biodiversity estimates (richness, abundance, composition) between studies and sampling sites. Point counts suffer from a trade-off between time bias and sampler bias: with an increasing number of observers, more simultaneous, and thus temporally unbiased, data points can be obtained, but the number of observer-specific, thus observer-biased, data points increases. The observer bias is commonly recognized (Sauer et al. 1994); it can lead to an under- or overestimation of the actual number of species present (from $81 \%$ to $132 \%$; Simons et al. 2007), and it has also been quantified by comparing interpretations of single observers to completely annotated and multiply checked sound recordings as a reference (Campbell and Francis 2011). In contrast, sound recorders incur no sampler bias in the raw audio data when the equipment and settings are identical. Their microphones are manufactured within given signal-tonoise ratio tolerances, even though it may change with time due to environmental stress (rainfall, temperature variations, mechanical shocks, etc.), thus requiring regular calibration (Turgeon et al. 2017). However, the raw audio data should be processed by the same interpreter to avoid an observer bias. Even though the bias between observers can be relatively low when using multiple interpreters (Rempel et al. 2005), crucially, it can be quantified thereafter by verifying the recordings.

Verification and updates. - To eliminate possible biases in the bird detection data, verification procedures allow confirming their quality, while updates can correct the data themselves (mainly species identifications). The verifiability of point counts is low as we are depending entirely on the identification skills, current physical state, and memory of a single observer. Especially in tropical regions, the many species vocalizing simultaneously makes correct identification of all individuals a challenging task. Moreover, auditory detections are sometimes uncertain (Mortimer and Greene 2017). When point count observations have corresponding photographic or audio evidence material, the observer bias can be lessened, but this is rarely done. The bias can also be corrected with high numbers of replicates, expertise checks, and observer shifts in one site (Lindenmayer et al. 2009). In contrast, with sound recordings, audio evidence is available at no additional cost; interpretation of recordings can be carried out whenever it is convenient, even by a single person. Reviewers can verify the data obtained from less experienced ornithologists (Wheeldon et al. 2019). Venier et al. (2012) showed that data from sound recordings can be updated by re-interpreting the recordings to correct the initial species identifications. Fully annotated sound recordings can serve as a basis for assessing the bias of different listeners and correct misidentifications (Campbell and Francis 2011). Thus, even when sound recordings are processed by different people, the result can be reviewed and standardized by one person, which is helpful in long-term monitoring projects.

Travel time.-Observers carrying out point counts need only one visit per survey replicate. In contrast, sound recorders need to be installed before they start recording and must be picked up for collecting the data or recharging batteries, even though some more advanced passive acoustic monitoring systems are more autonomous and eliminate that constraint (Aide et al. 2013, Sethi et al. 2018). However, it is also possible to install sound recorders, leave the sampling site, record sound, and take them back with one trip, in cases when human presence is known to affect birds, or when ornithologists are not available, or even when only few recorders are available. When recorders are installed and picked up by ornithologists, this can be combined with a point count (McGrann and Furnas, 2016), which can yield useful reference data for distance estimation (Darras et al. 2018b). Depending on the study design, either one of the survey methods could be more practical: if sampling replicates on consecutive days at the same site are needed, sound recorders will prove handy. If the number of sampling sites is high and replicate visits are few, either many recorders or frequent travels will be needed, so that point counts may be more efficient. Our cost analysis considers these aspects in its calculation (Fig. 4).

Scaling in space and time.-Temporal coverage is easily increased with autonomous sound recorders and this is one of the main advantages of these devices. Usually, the duration of point counts needs to be optimized so that all sites can be reached within the birds' activity window and sampled long enough, as there are only a limited number of sites that can be reached within one day. Acoustic surveys, however, allow for greater flexibility in scaling up sampling effort. Provided that multiple recorders are available, multiple sites can be sampled simultaneously. It is straightforward to record for long durations or multiple days only at the expense of data storage, energy supply, and data transfer time, all of which are cheap compared with specialized ornithological labor. Currently available recorders can record continuously for 7-25 d (Table 2). Some recorders have even higher autonomy by relying on solar panels for their energy supply. Transmitting data automatically through wireless networks enables sampling for even 

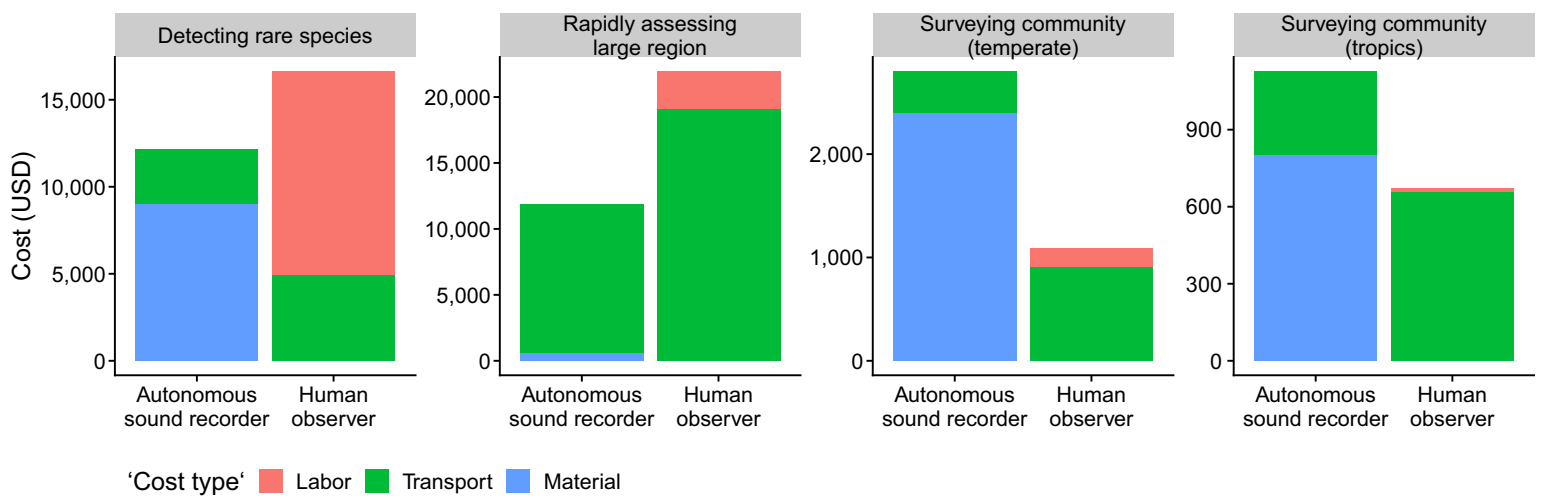

FIG. 4. Total costs (material, travel, and labor) for acquiring raw data with each survey method for different combinations of cost parameters characterizing four typical avian study types. We chose daily wages of 200 USD for experts and 120 USD for technicians; for the tropics, we chose 15 USD for experts and 10 USD for technicians. For detecting rare species, we chose 10 high-end recorders at 900 USD each, 120 min sampling per day for 14 days, transport times and costs per site of 15 minutes and 5 USD, and a total of 50 sites. For rapidly assessing a large region, we used 10 low-end recorders at 60 USD each, 15 min sampling per day for three days, transport times and costs per site of 30 minutes and 10 USD, and a total of 450 sites. For studies surveying the bird community, we chose 4 recorders, 10 min sampling per day for four days, transport times and costs per site of 15 minutes and 5 USD, and a total of 32 sites. For the temperate zone, we chose recorders that cost 600 USD each; for the tropics, we chose recorders that cost 200 USD each.

longer durations (Aide et al. 2013). Interestingly, choosing intermittent parts from long recordings enables to detect more species than a single continuous recording of the same duration would yield (Klingbeil and Willig 2015, Cook and Hartley 2018), due to temporal species turnover. In species occupancy modeling, the increased number of replicates also considerably improves site- level detectability, and overall accuracy and precision of state variables such as richness. For example, additional acoustic survey replicates doubled the alpha richness estimate of montane avian communities through occupancy modeling (McGrann and Furnas 2016), which was not possible previously with point counts only (McGrann et al. 2014).

TABLE 2. Overview of the currently available autonomous sound recorders that can sample the entire audible frequency range, along with their specifications, as of April 17, 2019.

\begin{tabular}{|c|c|c|c|c|c|c|c|}
\hline Model & Manufacturer & Channels & $\begin{array}{c}\text { Price } \\
(\mathrm{US} \$) \dagger\end{array}$ & $\begin{array}{c}\text { Power } \\
\text { autonomy } \\
\text { (hours) }\end{array}$ & Weight $(\mathrm{g}) \$$ & $\begin{array}{l}\text { Dimensions } \\
(\mathrm{cm})\end{array}$ & $\begin{array}{c}\text { Warranty } \\
\text { (yr) }\end{array}$ \\
\hline Audiomoth & $\begin{array}{l}\text { Open Acoustic } \\
\text { Devices (open } \\
\text { source) }\end{array}$ & 1 & $50 \#$ & 187 & 80 & $5.8 \times 4.8 \times 1.5$ & no \\
\hline BAR & Frontier Labs & 1 or 2 & 602 & 222 & 360 & $11 \times 13 \times 7$ & 1 \\
\hline BAR-LT & & 1 or 2 & 811 & & 890 & $11 \times 16 \times 7$ & 1 \\
\hline SM4 & $\begin{array}{l}\text { Wildlife } \\
\text { Acoustics }\end{array}$ & 2 & 849 & 205 & 1,300 & $21.8 \times 18.6 \times 7.8$ & 3 \\
\hline SM3Bat§ & & 2 & 2,187 & 161 & 3,200 & $32.4 \times 20 \times 6.5$ & 3 \\
\hline $\begin{array}{l}\text { Whitlock and } \\
\text { Christie (2016; } \\
\text { Solo), Turner et al. } \\
\text { (2015; ARUPI), } \\
\text { Sethi et al. (2017, } \\
\text { 2018), Beason et al. } \\
\text { (2018; AURITA) }\end{array}$ & $\begin{array}{l}\text { Raspberry-Pi- } \\
\text { based open- } \\
\text { source recorders }\end{array}$ & 1 or 2 & $160-296$ & variable & $\sim 600$ & $20 \times 8 \times 9.5$ & no \\
\hline Swift & $\begin{array}{l}\text { Cornell } \\
\text { University (non- } \\
\text { profit), Ithaca, } \\
\text { New York, USA }\end{array}$ & 1 & $250-300$ & 550 & $1,088-2,494$ & $\begin{array}{l}20.3 \times 12.7 \times 10 .^{-} \\
2-21.6 \times 17.1 \times- \\
10.2\end{array}$ & no \\
\hline
\end{tabular}

Note: A regularly updated version with more details is available from Darras (2019).

$\dagger$ With microphones, converted to US\$ on 19 July 2018.

\pm With batteries.

$\S$ recently discontinued.

- Technical support exists.

\# does not include case. 
Spatial coverage is also easily increased as recorders become more affordable. However, when recorders are scheduled for multiple repeated recordings, they cannot be used elsewhere except after an additional transportation. This potentially leads to a trade-off between increasing temporal coverage and spatial coverage but this issue is offset by the recent, lowest price point of US\$50 at which autonomous sound recorders can be purchased (Audiomoth; Open Acoustic Devices, UK) the following citation could be added: Hill et al. 2017, https://besjournals.online library.wiley.com/doi/full/10.1111/2041-210X.12955. For a given budget, 40 times more units can be purchased than when using the most expensive recorders, and even though the sound detection spaces should be smaller, these more numerous units would cover a much larger sampling area. In some cases, large coverages were achieved with the help of citizen scientists operating sound recording equipment (Jeliazkov et al. 2016). It also becomes feasible to conduct linear acoustic transects, analogous to the common line transect surveys conducted by human observers, but with all transect points sampled simultaneously. However, any spatial arrangement can be used: Random placement of recorders would allow sampling sites more independently, which simplifies statistical analysis and removes bias in spatial upscaling. With sufficient numbers of recorders, a complete, full-time coverage of a given territory can be achieved, leading to an enhanced version of territory mappings that are conducted by humans.

Expert labor- - It is costly to hire ornithologists for field surveys; demand is high during the short breeding season, and in some regions, experts may be unavailable, especially in the tropics (Wheeldon et al. 2019). Passive acoustic monitoring systems, however, can be installed and picked up by technical staff to assign experts to the interpretation of recordings only (Rempel et al. 2005). The units can be set up as quickly as humans need time for getting ready for a point count. Scheduling sound recorders also usually does not require programming experience, and programs can sometimes be saved onto storage media to be loaded by technical staff (e.g., Song Meters of Wildlife Acoustics, Maynard, MA, USA). Some custom open-source solutions do require some command-line input (e.g., Solo recorder; Whytock and Christie 2016). Thus, by following simple protocols, it is possible to gather raw audio data without the help of ornithologists; for analyzing these data, however, experts are still required.

Autonomous sound recorders allow for a more efficient use of expert ornithologists. When ornithologists are required to design and start new avian surveys in the field, they can carry out initial point counts to gather data about non-vocal species, as well as reference recordings for estimating bird detection distances more accurately (Darras et al. 2018b). Funds for taxonomic experts can be optimized to assign them only to processing or reviewing recordings, or even postponed until funds become available. Even non-experts can attain high accuracy levels when using automated species classification methods (Goyette et al. 2011), and sound recordings are easier to process with little ornithological experience, thus increasing the number of available surveyors (Kułaga and Budka 2019, Wheeldon et al. 2019). Moreover, data can be sent to ornithologists or accessed online from anywhere (see, for example, BioSounds, Fig. 2). Even citizen scientists have been mobilized to successfully sample Orthopterans to subsequently automatically detect focal species (Jeliazkov et al. 2016). It is often stated that identifying birds inside sound recordings is a time-consuming process, but the processing time can be halved by filtering out sections without bird vocalisations (Zhang et al. 2015, Eichinski and Roe 2017) and in some cases the "search space," the number of recordings that need to be screened, can be reduced by $94 \%$ (Potamitis et al. 2014). In analyses of selected species, acoustic recordings also require less time in the field and the lab (Holmes et al. 2014).

It is also possible to listen to a recording without interruption, thereby simulating a "blind" point count of the same duration. Such a procedure incurs the same labor cost as for a point count, or even less when considering that data can be entered directly in an electronic format. Altogether, we argue that the labor cost of processing audio data from autonomous sound recorders is entirely dependent on the researchers' needs and decisions. On the one hand, minimal sampling intensity and labor cost can be achieved that is identical with point counts (Venier et al. 2012). On the other hand, the full potential can be realized with maximal sampling intensity to find every single vocalization (Campbell and Francis 2011). Any other processing option in between is possible, but only autonomous sound recorders offer this choice. The trade-off of higher sampling intensity lies in the increased processing effort, which can be minimized with automated detection methods.

Automation. - Automated species identification is possible only with sound recordings; this procedure diminishes reliance on expert workforce and allows processing of large data sets in much less time than would be possible using human labor. Different open-source and commercial solutions for automated detection exist and it is widely recognized that automated analysis is the only practical solution to realize the full potential of longduration field recordings, as it allows processing longer recordings in an unattended way to increase detection chances. Usually, the focus has been on single species that can be detected with a measurable probability and accuracy (Brandes 2008). Night birds have also been preferably detected with automated methods (Shonfield et al. 2018), presumably because it is easier to detect calls in the typically lower and more constant ambient sound.

The field of automated species detection is burgeoning and has been reviewed recently (Priyadarshani et al. 2018). In that review, "recall" measures for automated 
detection are emphasized, as they describe the true positive rate of a particular method; recall rates reported by the publications had a relatively high median of $85 \%$. The tested methods are usually deemed to perform very accurately by their authors, and some disadvantage that they might have compared to manual identification can be made up by processing larger data sets. Automated detection can also expand species counts from manual processing by adding detections from longer recordings (Tegeler et al. 2012). However, the recordings used for benchmarking are sometimes not representative of realworld, noisier conditions (Priyadarshani et al. 2018). The efficiency of automated species detection methods also depends on the method used, the quality of the recordings, and the target species: efficiency compared to manual processing is sometimes equivalent or lower (Digby et al. 2013, Joshi et al. 2017). Nevertheless, rapid progress is being made and it is currently possible to rely only on the vocalisations contained within the field recordings to generate classifiers (Ovaskainen et al. 2018). The number of species that can be reliably identified computationally will undoubtedly increase. However, it is still challenging to handle complex song structures, noisy field conditions or distant calls (both resulting in low signal-to-noise ratios of the target vocalisations), overlapping calls of non-target species, and large song repertoires (Bardeli et al. 2010, Priyadarshani et al. 2018). To date, there are no fully automated methods allowing identification of all species of an entire bird community, even the most "intelligent" automated methods such as machine learning still require initial input and final checks from human experts. Although online audio bird databases are available, such as Xeno-Canto, and it is possible to use their reference recordings for generating classifiers (Araya-Salas and Smith-Vidaurre 2017), it is impossible to rely entirely on their birding community for identifying unknown bird species: experts should always be accounted for when planning acoustic avian studies (database available online). ${ }^{6}$

Material and labor costs. - Autonomous sound recorders generally entail higher material costs, while point counts entail higher labor costs. Point counts usually only require field gear; directional microphones and binoculars are optional. It is difficult to hire the same ornithologists throughout in long-term studies. Sound recorders, however, are purchased once and typically last for years if maintained properly, until irreparably broken or stolen, greatly facilitating long-term data compatibility. Autonomous sound recorders can be costly, but a variety of products exist (Table 2), from budget constructions (wa Maina et al. 2016, Whytock and Christie 2016) to commercial products (e.g., Wildlife Acoustics), spanning a price range of US\$50 to thousands of dollars. Still, it is important to plan for replacement costs of batteries, and especially microphones, which are exposed to the

${ }^{6}$ www.xeno-canto.org elements and which can degrade significantly over time. Microphones are also the most expensive components of recorders, but they can be assembled with open-source designs (Darras et al. 2018c). Altogether, the total costs of each survey method (for both labor and materials) are highly context dependent, but we estimated them for four different study types (Fig. 4), showing that when large spatial and temporal scales have to be covered, autonomous sound recorders are more cost effective than point counts, whereas the latter are cheaper for smaller-scale studies. We tried to keep the estimation simple and robust while accounting for the most important parameters, as the complexity of such calculations is not bounded by any objective criteria.

Mobility.-Some wilderness sites in forest, at high elevations, or unexplored regions can be difficult to reach. For point counts, the observer preferably has to be present on-site at dawn, which is often impossible or dangerous in inaccessible or unsafe areas. In contrast, placing autonomous sound recorders in such challenging conditions is easier: transport can occur any time without rush when conditions are best (during daylight), and the devices are usually weatherproof so that they can safely stay there for long periods of time. Autonomous sound recorders can reliably meet the programmed schedule as long as they are installed before recording. Furthermore, Prevost (2016) showed that sound recorders were amenable to installation on hot air balloons, due to their low size and weight. Also, deployment to inaccessible areas with unmanned aerial vehicles is feasible (Wilson et al. 2017), and installation on cars can also be envisaged (Jeliazkov et al. 2016). In the future, large geographical scales could also be sampled using autonomous wireless recorder networks that collect and transmit data wirelessly (Collins et al. 2006).

Sampling after rain.- Autonomous sound recorders suffer from a drawback when it is raining: many microphones are not weather- or waterproof and foam screens are commonly used for protection against water and wind. After rain, windscreens are soaked with water, which results in a loss of sensitivity and can take several hours to dry. This is a clear disadvantage and a technical challenge waiting for a solution. In wind-still regions, using acoustic vents with high water ingress protection ratings is a sensible alternative to the use of foam windscreens, and waterproof microphone elements can also be used (Darras et al. 2018c).

\section{OVERVIEW OF AUTONOMOUS SOUND RECORDERS AND THEIR TECHNICAL SPECIFICATIONS}

We provide an overview of the currently available recorders in Table 2. The technical specifications essentially determine the suitability for a particular study or application and are discussed in the following subsections. 
Commercial vs. open-source solutions. - Budget and time constraints determine whether solutions that work out of the box should be purchased or specially tailored recorders should be built. Even commercial recorders can have a steep learning curve, but building recorders from different components usually requires good technical and basic programming skills. Support or warranties are usually not available for non-commercial solutions, as they cost roughly an order of magnitude less. On the other side, custom-built solutions are more flexible, easily repaired or upgraded to meet the desired specifications. Both commercial and open-source solutions suffer from restricted product lifespans, as they get replaced by successor models (as governed by marketing strategy), or when their components become unavailable or discontinued.

Audio quality.-Audio quality is mainly determined by the number of microphones or recording channels, the signal-to-noise ratio of the microphones, and their height (Darras et al. 2018a), the latter being independent from the recorder itself. All but one of the recorders (Audiomoth) presented here can be used with cables to install microphones in the desired location, if necessary. However, the number of microphones cannot be changed and at least two microphones are necessary to record binaural cues, which give a more accurate spatial representation of the soundscape when listening.

The microphone itself is a crucial element as it is transducing sound energy into electrical energy. Its signal-to-noise ratio describes how faithfully and cleanly it is recording sound, and it is an inherent characteristic of the microphone model (within tolerances). Basically, the higher the signal-to-noise ratio, the higher the sound quality, even though signal amplifiers also affect the final sound quality slightly. Commercial vendors often do not disclose which microphones are used so that you have little knowledge or control over them. However, the acoustic ports are usually standard parts available through electronic retailers, so that cheaper, custombuilt solutions also work (Darras et al. 2018c).

The sampling frequency, when divided by two, indicates what maximum sound frequency can be recorded. All of the presented recorders are able to record sound at a sampling frequency of $44.1 \mathrm{kHz}$, which enables to record all audible sound. Some of them, however, can use higher sampling frequencies, which allows them to be used as ultrasound sampling devices for surveying bats, for instance, as long as suitable full-spectrum microphones are used (Darras et al. 2018c).

Storage and power--All recorders are autonomous only as far as storage is not full and batteries are not depleted. Fully autonomous solutions (power- and storage-wise) do exist (Aide et al. 2013, Sethi et al. 2018), but they are usually expensive, complicated to set up, and not for sale, so they are not covered here. We provided an estimate of the run time in approximately equivalent conditions without being able to test actual units in the field. Run time is determined by the batteries' capacity and the power consumption of the device, which is dependent on many factors (mainly the sampling rate and recording schedule). Most devices' run time can be considerably extended: only two devices cannot be connected with an external power source such as car batteries or solar panels.

All recorders record sound in WAV format, which is an uncompressed, qualitatively lossless, audio format. Some have proprietary lossless and lossy compressed audio formats (Wildlife Acoustics), and proprietary software can be required for conversion or playback, and only one uses an open-source lossless compression format (FLAC, Bioacoustic Recorder; Frontier Labs, Brisbane, Australia). Compression can reduce or increase power consumption, depending on whether the processor or the storage-writing hardware is more efficient, but will always result in storage space savings, which can be crucial.

Physical specifications and options. - The size and weight obviously affect how transportable the units are, and also how sturdy their support has to be. All units considered here are portable, but smaller recorders can be transported in greater quantities in simple backpacks and also strapped to tree branches, drones, or animals. Depending on their number, bulky recorders, however, can make it necessary to use cars for transporting them.

Some units have integrated geopositioning sensors, which are especially useful when recorders are used as mobile units in transects. Spatial coordinates also help ascertain the location where the recording took place.

\section{Challenges, Perspectives, AND KNOWLedge GAPS}

Our review covered all advantages that were identified independently by Abrahams (2018) while some disadvantages have been mitigated. Currently, autonomous sound recorders are still used in variable ways, as there is no widely accepted standard, although best practice recommendations have been made for maximum compatibility and comparability with point counts (Abrahams 2018, Darras et al. 2018a). On the one hand, the wide range of available hardware solutions reflects the varied needs and possibilities of that technology. On the other hand, comparisons of studies that use different recorders are not straightforward as different recording systems likely have different detection ranges (Darras et al. 2018a), even though they can be measured and standardized (Darras et al. 2016, Yip et al. 2017). For the moment however, no standard survey protocols are used (Gibb et al. 2018), and very few studies standardize detection spaces, although they are considerably affected by the sampling sites themselves (Darras et al. 2016a). Similarly, for processing audio recordings, there are no widely accepted standards for assessing the performance of recognizers (Knight et al. 2017), which hampers a 
unified evaluation of the software for automated species identification, even though some benchmark data sets are available (Priyadarshani et al. 2018, Morfi et al. 2018:4).

Covering large spatiotemporal scales is an important challenge that has been tackled with acoustic surveys (Furnas and Callas 2015). However, it is still hampered by bottlenecks: limited power autonomy, limited storage capacity, and labor-intensive transport and installation of recorders. Even though almost fully autonomous systems have been developed (Aide et al. 2013, Sethi et al. 2018), there are no easily implemented solutions available yet. Power limitations are being released gradually through the use of solar panels and power-efficient components, but storage issues are still costly to circumvent. Little data packages can be transmitted through the mobile network with some commercial recorders (Song Meters, Wildlife Acoustics) and open recording systems (Sethi et al. 2018), but no attempt has been made yet to use multiple recorders to transmit data locally in networks, at the only expense of power, like has been done with other sensors (Collins et al. 2006). Transmitting data via low-orbit satellites can be envisioned too (ICARUS Initiative 2019). Lastly, deploying acoustic recorders on large scales with drones would significantly improve the reach of such systems into little-explored areas.

For the moment, autonomous sound recorders inherently, and obviously, generate only aural detections. In the future, it is imaginable to combine them with photographic sensors similar to camera traps, to design devices that make maximal use of all visible and audible events around them. Camera traps can already be set up to take pictures at specific times and some models also record audio while making videos. It has already been shown that it is possible to combine data from camera traps and sound recorders (Buxton et al. 2018a). It is conceivable to create hybrid devices that would entirely mimic a human observer by yielding both visual and audio detections. This would enable detecting not only sonant animals but also larger, seldom-vocalizing animals, and it could also complement the audio data by giving pictures of the sampled animals to support species identification.

\section{Conclusion}

For identical sampling durations, sound recorders are on par with human observers to sample birds, and if used properly, they can surpass them. Autonomous sound recorders are more practical, scalable, consistent, and deliver verifiable results, but their main advantage lies in their potential to collect much more data than human observers. Identification algorithms for speciesspecific automated detection are developed at a rapid pace and tackle these growing amounts of data (Priyadarshani et al. 2018). The big data volume presents new challenges for storage and documentation (Gaunt et al. 2005), even though standard solutions have been proposed for manage these (Roch et al. 2016). Considering the largely context-specific costs of avian studies, recorders are probably more efficient for conservation-focused work and large-scale assessments, while small bird community surveys can be relatively more efficient with human observers. Even so, at the time of writing, machines do not yet replace humans. One might worry that sound recording devices put ornithologists out of a job, but it is more likely that ornithologists will just be able to redirect their time to less repetitive activities. Still, all audio data should ultimately be vetted by experts before conclusions are published, and as bird survey data collection becomes easier and relies more on "citizen scientists" and other non-experts to acquire, the demand for experts could actually increase. Technology could also provide ornithologists greater work flexibility as audio data can be analysed at any time, from anywhere. Ornithologists will continue to fulfil an indispensable function in the field and in the office observing bird behavior in the field and habitats, designing studies, improving our understanding of avian ecology and evolution, and developing strategies for effective conservation.

\section{ACKNowledgments}

We declare that there are no conflicts of interest. This study was financed by the Deutsche Forschungsgemeinschaft (DFG) in the framework of the collaborative German-Indonesian research project CRC990. We warmly thank all collaborators who shared data and provided additional explanations to carry out our meta-analysis, as well as two anonymous reviewers who provided invaluable critical feedback. We thank the following persons and organizations for granting us access to and use of their properties: village leaders and local plot owners.

\section{Literature Cited}

Abrahams, C. 2018. Bird bioacoustic surveys-developing a standard protocol. In Practice 102:20-23.

Abrahams, C. 2019. Comparison between lek counts and bioacoustic recording for monitoring Western Capercaillie (Tetrao urogallus L.). Journal of Ornithology 160:685-697.

Ahumada, J. A., et al. 2011. Community structure and diversity of tropical forest mammals: data from a global camera trap network. Philosophical Transactions of the Royal Society B 366:2703-2711.

Aide, T. M., C. Corrada-Bravo, M. Campos-Cerqueira, C. Milan, G. Vega, and R. Alvarez. 2013. Real-time bioacoustics monitoring and automated species identification. PeerJ 1:e103.

Alldredge, M. W., T. R. Simons, and K. H. Pollock. 2007. A field evaluation of distance measurement error in auditory avian point count surveys. Journal of Wildlife Management 71:2759-2766.

Alquezar, R. D., and R. B. Machado. 2015. Comparisons between autonomous acoustic recordings and avian point counts in open woodland savanna. Wilson Journal of Ornithology 127:712-723.

Araya-Salas, M., and G. Smith-Vidaurre. 2017. warbleR: an R package to streamline analysis of animal acoustic signals. Methods in Ecology and Evolution 8:184-191.

Bardeli, R., D. Wolff, F. Kurthd, M. Koch, K.-H. Tauchert, and K.-H. Frommolt. 2010. Pattern Recognition Letters 
Detecting bird sounds in a complex acoustic environment and application to bioacoustic monitoring. Pattern Recognition Letters. 31:1524-1534.

Barré, K., I. Le Viol, R. Julliard, J. Pauwels, S. E. Newson, J. Julien, F. Claireau, C. Kerbiriou, and Y. Bas. 2019. Accounting for automated identification errors in acoustic surveys. Methods in Ecology and Evolution. https://doi.org/2041210x.13198

Bart, J., and J. D. Schoultz. 1984. Reliability of singing bird surveys: changes in observer efficiency with avian density. Auk 101:307-318.

Beason, R. D., R. Riesch, and J. Koricheva. 2018. AURITA: an affordable, autonomous recording device for acoustic monitoring of audible and ultrasonic frequencies. Bioacoustics 28:381-396.

Beer, C. G. 1971. Individual recognition of voice in the social behavior of birds. Pages 27-74 in R. A. Hinde, E. Shaw, and D. S. Lehrman, editors. Advances in the study of behavior. Academic Press.

Bibby, C. J., N. D. Burgess, and D. A. Hill. 2000. Bird census techniques. Revised edition. Academic Press, London, UK.

Blumstein, D. T., et al. 2011. Acoustic monitoring in terrestrial environments using microphone arrays: applications, technological considerations and prospectus: Acoustic monitoring. Journal of Applied Ecology 48:758-767.

Bombaci, S., and L. Pejchar. 2019. Using paired acoustic sampling to enhance population monitoring of New Zealand's forest birds. New Zealand Journal of Ecology 43:3356.

Bower, J. L., and C. Clark. 2005. A field test of the accuracy of a passive acoustic location system. Bioacoustics 15:1-14.

Brandes, T. S. 2008. Automated sound recording and analysis techniques for bird surveys and conservation. Bird Conservation International 18:S163-S173.

Buckland, S. T., S. J. Marsden, and R. E. Green. 2008. Estimating bird abundance: making methods work. Bird Conservation International 18:S91-S108.

Buxton, R. T., P. E. Lendrum, K. R. Crooks, and G. Wittemyer. 2018a. Pairing camera traps and acoustic recorders to monitor the ecological impact of human disturbance. Global Ecology and Conservation 16:e0493.

Buxton, R. T., M. F. McKenna, M. Clapp, E. Meyer, E. Stabenau, L. M. Angeloni, K. Crooks, and G. Wittemyer. 2018b. Efficacy of extracting indices from large-scale acoustic recordings to monitor biodiversity. Conservation Biology 32:1174-1184.

Bye, S. L., R. J. Robel, and K. E. Kemp. 2001. Effects of human presence on vocalizations of grassland birds in Kansas. Prairie Naturalist 33:249-256.

Campbell, M., and C. M. Francis. 2011. Using stereo-microphones to evaluate observer variation in North American Breeding Bird Survey point counts. Auk 128:303-312.

Campbell, M., and C. M. Francis. 2012. Using microphone arrays to examine effects of observers on birds during point count surveys. Journal of Field Ornithology 83:391-402.

Catchpole, C., and P. J. B. Slater. 2008. Bird song: biological themes and variations. Second edition. Cambridge University Press, Cambridge, UK.

Celis-Murillo, A., J. L. Deppe, and M. P. Ward. 2012. Effectiveness and utility of acoustic recordings for surveying tropical birds. Journal of Field Ornithology 83:166-179.

Chambert, T., J. H. Waddle, D. A. W. Miller, S. C. Walls, and J. D. Nichols. 2018. A new framework for analysing automated acoustic species detection data: Occupancy estimation and optimization of recordings post-processing. Methods in Ecology and Evolution 9:560-570.

Collins, S. L., et al. 2006. New opportunities in ecological sensing using wireless sensor networks. Frontiers in Ecology and the Environment 4:402-407.
Cook, A., and S. Hartley. 2018. Efficient sampling of avian acoustic recordings: intermittent subsamples improve estimates of single species prevalence and total species richness. Avian Conservation and Ecology 13:21. https://doi.org/10. 5751/ACE-01221-130121

Cunningham, R. B., D. B. Lindenmayer, and B. D. Lindenmayer. 2004. Sound recording of bird vocalisations in forests. I. Relationships between bird vocalisations and point interval counts of bird numbers - a case study in statistical modeling. Wildlife Research 31:195.

Darras, K. F. A. 2019. Autonomous sound recorders: overview and meta-analysis. Open Science Framework. https://doi.org/ 10.17605/osf.io/tsyv7

Darras, K., P. Pütz, K. Rembold. Fahrurrozi, and T. Tscharntke. 2016. Measuring sound detection spaces for acoustic animal sampling and monitoring. Biological Conservation 201:29-37.

Darras, K., P. Batáry, B. Furnas, A. Celis-Murillo, S. L. V. Wilgenburg, Y. A. Mulyani, and T. Tscharntke. 2018a. Comparing the sampling performance of sound recorders versus point counts in bird surveys: A meta-analysis. Journal of Applied Ecology 55:2575-2586.

Darras, K., B. Furnas, I. Fitriawan, Y. Mulyani, and T. Tscharntke. 2018b. Estimating bird detection distances in sound recordings for standardizing detection ranges and distance sampling. Methods in Ecology and Evolution 9:19281938.

Darras, K., B. Kolbrek, A. Knorr, and V. Meyer. 2018c. Assembling cheap, high-performance microphones for recording terrestrial wildlife: the Sonitor system. F1000Research 7:1984.

Deichmann, J. L., et al. 2018. It's time to listen: there is much to be learned from the sounds of tropical ecosystems. Biotropica 50:713-718.

Denes, F. V., J. L. Tella, and S. R. Beissinger. 2018. Revisiting methods for estimating parrot abundance and population size. Emu 118:67-79.

Depraetere, M., S. Pavoine, F. Jiguet, A. Gasc, S. Duvail, and J. Sueur. 2012. Monitoring animal diversity using acoustic indices: Implementation in a temperate woodland. Ecological Indicators 13:46.

Digby, A., M. Towsey, B. D. Bell, and P. D. Teal. 2013. A practical comparison of manual and autonomousmethods for acoustic monitoring. Methods in Ecology and Evolution 4:675-683.

Ehnes, M., and J. Foote. 2015. Comparison of autonomous and manual recording methods for discrimination of individually distinctive Ovenbird songs. Bioacoustics 24:111-121.

Eichinski, P., and P. Roe. 2017. Clustering and Visualization of Long-Duration Audio Recordings for Rapid Exploration Avian Surveys. Pages 168-176 2017 IEEE 13th International Conference on e-Science (e-Science), IEEE, Auckland, New Zealand.

Emlen, J. T., and M. J. DeJong. 1992. Counting birds: the problem of variable hearing abilities . Journal of Field Ornithology 63:26-31.

Fernández-Juricic, E., M. D. Jimenez, and E. Lucas. 2001. Alert distance as an alternative measure of bird tolerance to human disturbance: implications for park design. Environmental Conservation 28:263-269.

Frommolt, K.-H. 2017. Information obtained from long-term acoustic recordings: applying bioacoustic techniques for monitoring wetland birds during breeding season. Journal of Ornithology 158:659-668.

Furnas, B. J., and R. L. Callas. 2015. Using automated recorders and occupancy models to monitor common forest birds across a large geographic region. Journal of Wildlife Management 79:325-337. 
Furnas, B. J., and M. C. McGrann. 2018. Using occupancy modeling to monitor dates of peak vocal activity for passerines in California. Condor 120:188-200.

Gates, G. A., and J. H. Mills. 2005. Presbycusis. Lancet 366:1111-1120.

Gaunt, S. L. L., D. A. Nelson, M. S. Dantzker, G. F. Budney, J. W. Bradbury, and R. M. Zink. 2005. New directions for bioacoustics collections. Auk 122:984-987.

Gibb, R., E. Browning, P. Glover-Kapfer, and K. E. Jones. 2018. Emerging opportunities and challenges for passive acoustics in ecological assessment and monitoring. Methods in Ecology and Evolution 10:169-185.

Goyette, J. L., R. W. Howe, A. T. Wolf, and W. D. Robinson. 2011. Detecting tropical nocturnal birds using automated audio recordings. Journal of Field Ornithology 82:279-287.

Gutzwiller, K. J., and H. A. Marcum. 1993. Avian responses to observer clothing color: caveats from winter point counts. Wilson Bulletin 105:628-636.

Haselmayer, J., and J. S. Quinn. 2000. A comparison of point counts and sound recording as bird survey methods in Amazonian southeast Peru. Condor 102:887-893.

Hedley, R., Y. Huang, and K. Yao. 2017. Direction-of-arrival estimation of animal vocalizations for monitoring animal behavior and improving estimates of abundance. Avian Conservation and Ecology 12

Hingston, A., T. Wardlaw, S. Baker, and G. Jordan. 2018. Data obtained from acoustic recording units and from field observer point counts of Tasmanian forest birds are similar but not the same. Australian Field Ornithology 35:30-39.

Hobson, K. A., R. S. Rempel, H. Greenwood, B. Turnbull, and S. L. Van Wilgenburg. 2002. Acoustic surveys of birds using electronic recordings: new potential from an omnidirectional microphone system. Wildlife Society Bulletin 30:709-720.

Holmes, S. B., K. A. McIlwrick, and L. A. Venier. 2014. Using automated sound recording and analysis to detect bird species-at-risk in southwestern Ontario woodlands. Wildlife Society Bulletin 38:591-598.

Hutto, R. L., and S. L. Mosconi. 1981. Lateral detectability profiles for line transect bird censuses: some problems and an alternative. Studies in Avian Biology 6:382-387.

Hutto, R. L., and R. J. Stutzman. 2009. Humans versus autonomous recording units: a comparison of point-count results. Journal of Field Ornithology 80:387-398.

ICARUS Initiative. 2019. https://icarusinitiative.org/

Iknayan, K. J., M. W. Tingley, B. J. Furnas, and S. R. Beissinger. 2014. Detecting diversity: emerging methods to estimate species diversity. Trends in Ecology \& Evolution 29:97-106.

James, K. L., N. P. Randall, and N. R. Haddaway. 2016. A methodology for systematic mapping in environmental sciences. Environmental Evidence 5:7.

Jeliazkov, A., Y. Bas, C. Kerbiriou, J.-F. Julien, C. Penone, and I. Le Viol. 2016. Large-scale semi-automated acoustic monitoring allows to detect temporal decline of bush-crickets. Global Ecology and Conservation 6:208-218.

Jorge, F. C., C. G. Machado, S. S. da Cunha Nogueira, and S. L. G. Nogueira-Filho. 2018. The effectiveness of acoustic indices for forest monitoring in Atlantic rainforest fragments. Ecological Indicators 91:71-76.

Joshi, K. A., R. A. Mulder, and K. M. C. Rowe. 2017. Comparing manual and automated species recognition in the detection of four common south-east Australian forest birds from digital field recordings. Emu - Austral Ornithology 117(3): 233-246. https://doi.org/10.1080/01584197.2017.1298970

Klingbeil, B. T., and M. R. Willig. 2015. Bird biodiversity assessments in temperate forest: the value of point count versus acoustic monitoring protocols. PeerJ 3:e973.
Knight, E., K. Hannah, G. Foley, C. Scott, R. Brigham, and E. Bayne. 2017. Recommendations for acoustic recognizer performance assessment with application to five common automated signal recognition programs. Avian Conservation and Ecology 12.

Koehler, J., M. Jansen, A. Rodriguez, P. J. R. Kok, L. F. Toledo, M. Emmrich, F. Glaw, C. F. B. Haddad, M.-O. Roedel, and M. Vences. 2017. The use of bioacoustics in anuran taxonomy: theory, terminology, methods and recommendations for best practice. Zootaxa 4251:1-124.

Kułaga, K., and M. Budka. 2019. Bird species detection by an observer and an autonomous sound recorder in two different environments: Forest and farmland. PLoS ONE 14: $\mathrm{e} 0211970$.

Leach, E. C., C. J. Burwell, L. A. Ashton, D. N. Jones, and R. L. Kitching. 2016. Comparison of point counts and automated acoustic monitoring: detecting birds in a rainforest biodiversity survey. Emu-Austral Ornithology 116:305-309.

Lellouch, L., S. Pavoine, F. Jiguet, H. Glotin, and J. Sueur. 2014. Monitoring temporal change of bird communities with dissimilarity acoustic indices. Methods in Ecology and Evolution 5:495-505.

Lindenmayer, D. B., J. T. Wood, and C. MacGregor. 2009. Do observer differences in bird detection affect inferences from large-scale ecological studies? Emu 109:100-106.

Lynch, E., L. Angeloni, K. Fristrup, D. Joyce, and G. Wittemyer. 2013. The use of on-animal acoustical recording devices for studying animal behavior. Ecology and Evolution 3:2030 2037.

MacKenzie, D. I. 2006. Occupancy estimation and modeling: inferring patterns and dynamics of species occurrence. Academic Press, Cambridge, MA.

MacKenzie, D. I., and J. D. Nichols. 2004. Occupancy as a surrogate for abundance estimation. Animal Biodiversity and Conservation 27:7.

Magurran, A. E., S. R. Baillie, S. T. Buckland, J. M. Dick, D. A. Elston, E. M. Scott, R. I. Smith, P. J. Somerfield, and A. D. Watt. 2010. Long-term datasets in biodiversity research and monitoring: assessing change in ecological communities through time. Trends in Ecology \& Evolution 25:574-582.

Mammides, C., E. Goodale, S. K. Dayananda, L. Kang, and J. Chen. 2017. Do acoustic indices correlate with bird diversity? Insights from two biodiverse regions in Yunnan Province, south China. Ecological Indicators 82:470-477.

McGrann, M. C., and B. J. Furnas. 2016. Divergent species richness and vocal behavior in avian migratory guilds along an elevational gradient. Ecosphere 7:e01419.

McGrann, M., M. Tingley, J. Thorne, D. Elliott-Fisk, and A. McGrann. 2014. Heterogeneity in avian richness-environment relationships along the Pacific Crest Trail. Avian Conservation and Ecology 9:8.

Merchant, N. D., K. M. Fristrup, M. P. Johnson, P. L. Tyack, M. J. Witt, P. Blondel, and S. E. Parks. 2015. Measuring acoustic habitats. Methods in Ecology and Evolution 6:257-265.

Morfi, V., Y. Bas, H. Pamuła, H. Glotin, and D. Stowell. 2018. NIPS4Bplus: a richly annotated birdsong audio dataset. arXiv:1811.02275 [cs, eess].

Mortimer, J. A., and T. C. Greene. 2017. Investigating bird call identification uncertainty using data from processed audio recordings. New Zealand Journal of Ecology 41:126-133.

Ovaskainen, O., U. M. de Camargo, and P. Somervuo. 2018. Animal sound identifier (ASI): software for automated identification of vocal animals. Ecology Letters 21:1244-1254.

Parmesan, C. 2007. Influences of species, latitudes and methodologies on estimates of phenological response to global warming. Global Change Biology 13:1860-1872. 
Patricelli, G. L., M. S. Dantzker, and J. W. Bradbury. 2007. Differences in acoustic directionality among vocalizations of the male red-winged blackbird (Agelaius pheoniceus) are related to function in communication. Behavioral Ecology and Sociobiology 61:1099-1110.

Pijanowski, B. C., L. J. Villanueva-Rivera, S. L. Dumyahn, A. Farina, B. L. Krause, B. M. Napoletano, S. H. Gage, and N. Pieretti. 2011. Soundscape ecology: the science of sound in the landscape. BioScience 61:203-216.

Potamitis, I., S. Ntalampiras, O. Jahn, and K. Riede. 2014. Automatic bird sound detection in long real-field recordings: Applications and tools. Applied Acoustics 80:1-9.

Prabowo, W. E., K. Darras., Y. Clough., M. Toledo-Hernandez., R. Arlettaz., Y. A. Mulyani, and T. Tscharntke. 2016. Bird Responses to Lowland Rainforest Conversion in Sumatran Smallholder Landscapes. Indonesia. PLoS ONE 11: e0154876. https://doi.org/10.1371/journal.pone.0154876

Prevost, S. C. 2016. Estimating avian populations with passive acoustic technology and song behavior. Master's Thesis, University of Tennessee.

Priyadarshani, N., S. Marsland, and I. Castro. 2018. Automated birdsong recognition in complex acoustic environments: a review. Journal of Avian Biology 49:jav-01447.

Ptacek, L., L. Machlica, P. Linhart, P. Jaska, and L. Muller. 2016. Automatic recognition of bird individuals on an open set using as-is recordings. Bioacoustics 25:55-73.

Rempel, R., K. Hobson, G. Holborn, S. Van Wilgenburg, and J. Elliott. 2005. Bioacoustic monitoring of forest songbirds interpreter variability and effects of configuration and digital processing methods in the laboratory. Journal of Field Ornithology 76:1-11.

Roch, M. A., et al. 2016. Management of acoustic metadata for bioacoustics. Ecological Informatics 31:122-136.

Royle, J. A., and W. A. Link. 2006. Generalized site occupancy models allowing for false positive and false negative errors. Ecology 87:835-841.

Royle, J. A., and J. D. Nichols. 2003. Estimating abundance from repeated presence-absence data or point counts. Ecology 84:777-790

Sauer, J. R., B. G. Peterjohn, and W. A. Link. 1994. Observer differences in the North American breeding bird survey. Auk 111:50-62.

Sebastian-Gonzalez, E., R. J. Camp, A. M. Tanimoto, P. M. de Oliveira, B. B. Lima, T. A. Marques, and P. J. Hart. 2018. Density estimation of sound-producing terrestrial animals using single automatic acoustic recorders and distance sampling. Avian Conservation and Ecology 13:7.

Sedláček, O., J. Vokurková, M. Ferenc, E. N. Djomo, T. Albrecht, and D. Hořák. 2015. A comparison of point counts with a new acoustic sampling method: a case study of a bird community from the montane forests of Mount Cameroon. Ostrich 86:213-220.

Sethi, S. S., R. M. Ewers, N. S. Jones, D. Orme, and L. Picinali. 2018. Robust, real-time and autonomous monitoring of ecosystems with an open, low-cost, networked device. bioRxiv 9:2383-2387.

Sethi, S. S., R. M. Ewers, N. S. Jones, C. D. L. Orme, and L. Picinali. 2018. Robust, real-time and autonomous monitoring of ecosystems with an open, low-cost, networked device. Methods in Ecology and Evolution 9:2383-2387.

Shonfield, J., and E. M. Bayne. 2017. Autonomous recording units in avian ecological research: current use and future applications. Avian Conservation and Ecology 12:14. https:// doi.org/10.5751/ACE-00974-120114

Shonfield, J., S. Heemskerk, and E. M. Bayne. 2018. Utility of automated species recognition for acoustic monitoring of owls. Journal of Raptor Research 52:42-55.
Simons, T. R., M. W. Alldredge, K. H. Pollock, J. M. Wettroth, and A. M. Dufty. 2007. Experimental analysis of the auditory detection process on avian point counts. Auk 124:986-999.

Sueur, J., S. Pavoine, O. Hamerlynck, and S. Duvail. 2008. Rapid acoustic survey for biodiversity appraisal. PLoS ONE 3:e4065.

Sugai, L. S. M., T. S. F. Silva, J. W. Ribeiro, and D. Llusia. 2019. Terrestrial passive acoustic monitoring: review and perspectives. BioScience 69:15-25.

Swiston, K. A., and D. J. Mennill. 2009. Comparison of manual and automated methods for identifying target sounds in audio recordings of Pileated, Pale-billed, and putative Ivory-billed woodpeckers. Journal of Field Ornithology 80:42-50.

Tegeler, A. K., M. L. Morrison, and J. M. Szewczak. 2012. Using extended-duration audio recordings to survey avian species. Wildlife Society Bulletin 36:21-29.

Teixeira, D., M. Maron, and B. J. VanRensburg. 2019. Bioacoustic monitoring of animal vocalbehavior for conservation. Conservation Science and Practice. e72. https://doi.org/10. $1111 / \operatorname{csp} 2.72$

Teuscher, M., M. Vorlaufer, M. Wollni, U. Brose, Y. Mulyani, and Y. Clough. 2015. Trade-offs between bird diversity and abundance, yields and revenue in smallholder oil palm plantations in Sumatra, Indonesia. Biological Conservation 186:306-318.

Thompson, W. L., G. C. White, and C. Gowan. 1998. Monitoring vertebrate populations. First edition. Academic Press, San Diego, California, USA.

Thompson, S. J., C. M. Handel, and L. B. Mcnew. 2017. Autonomous acoustic recorders reveal complex patterns in avian detection probability. Journal of Wildlife Management 81:1228-1241.

Tingley, M. W., M. S. Koo, C. Moritz, A. C. Rush, and S. R. Beissinger. 2012. The push and pull of climate change causes heterogeneous shifts in avian elevational ranges. Global Change Biology 18:3279-3290.

Toms, J. D., F. K. A. Schmiegelow, S. J. Hannon, and M.-A. Villard. 2006. Are point counts of boreal songbirds reliable proxies for more intensive abundance estimators? Auk $123: 438-454$

Turgeon, P., S. Van Wilgenburg, and K. Drake. 2017. Microphone variability and degradation: implications for monitoring programs employing autonomous recording units. Avian Conservation and Ecology 12:9. https://doi.org/10.5751/ ACE-00958-120109

Turner, A. 2015. ARUPI-a low-cost automated recording unit/autonomous recording unit (ARU) for soundscape ecologists. http://www.instructables.com/id/ARUPi-A-Low-CostAutomated-Recording-Unit-for-Soun/

Wilgenburg, Van, and Steven \& Solymos, Peter \& Kardynal, Kevin \& Frey, Matthew. 2017. Paired sampling standardizes point count data from humans and acoustic recorders. Avian Conservation and Ecology. 12:13. doi:10.5751/ACE-00975120113.

Venier, L. A., S. B. Holmes, G. W. Holborn, K. A. Mcilwrick, and G. Brown. 2012. Evaluation of an automated recording device for monitoring forest birds. Wildlife Society Bulletin 36:30-39.

Vold, S. T., C. M. Handel, and L. B. Mcnew. 2017. Comparison of acoustic recorders and field observers for monitoring tundra bird communities: acoustic monitoring of tundra-breeding birds. Wildlife Society Bulletin 41:566-576.

wa Maina, C., D. Muchiri, and P. Njoroge. 2016. Cost effective acoustic monitoring of biodiversity and bird populations in Kenya. bioRxiv 072546 .

Wheeldon, A., H. L. Mossman, M. J. P. Sullivan, J. Mathenge, and S. R. de Kort. 2019. Comparison of acoustic and traditional point count methods to assess bird diversity and 
composition in the Aberdare National Park, Kenya. African Journal of Ecology 57:168-176.

Whytock, R. C., and J. Christie. 2016. Solo: an open source, customizable and inexpensive audio recorder for bioacoustic research. Methods in Ecology and Evolution 8:308-312.

Wilkinson, M. D., et al. 2016. The FAIR guiding principles for scientific data management and stewardship. Comments and Opinion. https://www.nature.com/articles/sdata201618

Wilson, A. M., J. Barr, and M. Zagorski. 2017. The feasibility of counting songbirds using unmanned aerial vehicles. Auk 134:350-362.

Wimmer, J., M. Towsey, P. Roe, and I. Williamson. 2013. Sampling environmental acoustic recordings to determine bird species richness. Ecological Applications 23:1419-1428.
Yip, D., L. Leston, E. Bayne, P. Sólymos, and A. Grover. 2017. Experimentally derived detection distances from audio recordings and human observers enable integrated analysis of point count data. Avian Conservation and Ecology 12:11. https://doi.org/10.5751/ACE-00997-120111

Yip, D. A., E. C. Knight, E. Haave-Audet, S. J. Wilson, C. Charchuk, C. D. Scott, P. Sólymos, and E. M. Bayne. 2019. Sound level measurements from audio recordings provide objective distance estimates for distance sampling wildlife populations. Remote Sensing in Ecology and Conservation.

Zhang, L., M. Towsey, P. Eichinski, J. Zhang, and P. Roe. 2015. Assistive classification for improving the efficiency of avian species richness surveys. Pages 1-6 in Data science and advanced analytics (DSAA), 2015. 36678 2015. IEEE International Conference on IEEE.

\section{SUPPORTING INFORMATION}

Additional supporting information may be found online at: http://onlinelibrary.wiley.com/doi/10.1002/eap.1954/full

\section{Data Availability}

Data are available from the Open Science Framework: https://doi.org/10.17605/osf.io/tsyv7. 